\title{
Analysis of the rupture process of the 1995 Kobe earthquake using a 3D velocity structure
}

\author{
Yujia Guo ${ }^{1}$, Kazuki Koketsu ${ }^{1}$, and Taichi Ohno ${ }^{2}$ \\ ${ }^{1}$ Earthquake Research Institute, University of Tokyo, 1-1-1 Yayoi, Bunkyo-ku, Tokyo 113-0032, Japan \\ ${ }^{2}$ OYO RMS Corporation, 4-9-9, Akasaka, Minato-ku, Tokyo 107-0052, Japan
}

(Received March 11, 2013; Revised July 16, 2013; Accepted July 19, 2013; Online published December 6, 2013)

\begin{abstract}
A notable feature of the 1995 Kobe (Hyogo-ken Nanbu) earthquake is that violent ground motions occurred in a narrow zone. Previous studies have shown that the origin of such motions can be explained by the 3D velocity structure in this zone. This indicates not only that the 3D velocity structure significantly affects strong ground motions, but also that we should consider its effects in order to determine accurately the rupture process of the earthquake. Therefore, we have performed a joint source inversion of strong-motion, geodetic, and teleseismic data, where 3D Green's functions were calculated for strong-motion and geodetic data in the Osaka basin. Our source model estimates the total seismic moment to be about $2.1 \times 10^{19} \mathrm{~N} \mathrm{~m}$ and the maximum slip reaches $2.9 \mathrm{~m}$ near the hypocenter. Although the locations of large slips are similar to those reported by Yoshida et al. (1996), there are quantitative differences between our results and their results due to the differences between the 3D and 1D Green's functions. We have also confirmed that our source model realized a better fit to the strong motion observations, and a similar fit as Yoshida et al. (1996) to the observed static displacements.
\end{abstract}

Key words: Kobe earthquake, rupture process, 3D Green's functions.

\section{Introduction}

The Kobe (Hyogo-ken Nanbu) earthquake, with a JMA magnitude of 7.3, occurred at 5:46 on January 17, 1995 (JST), and claimed more than 6,000 lives. The damaging ground motions with a JMA intensity of 7 were generated in a narrow zone called the "damage belt" of the Kobe area. Kawase (1996) concluded that the "damage belt" resulted from the constructive interference of direct $S$-waves and basin-edge-induced diffracted/Rayleigh waves. Furumura and Koketsu (1998) showed that this zone arises from strong amplification and ray bending in the sedimentary basin below Kobe city in conjunction with the multipathing effects at a basin/bedrock boundary. These previous studies imply that the ground-motion amplification in the Kobe area was significantly affected by a 3D velocity structure such as a basin edge. Thus, we should inevitably consider its effects in precisely determining the rupture process of this earthquake.

In some previous studies (e.g., Hashimoto et al., 1996; Ide et al., 1996; Kikuchi and Kanamori, 1996; Sekiguchi et al., 2000) separate inversions of static displacement, teleseismic body waves, or strong motions were performed to analyze the rupture process of this earthquake. In these studies, half-space velocity structure models were used for calculating Green's functions of static displacements, and 1D stratified velocity structure models were used for those of teleseismic body waves or strong motions. In addition to

Copyright (C) The Society of Geomagnetism and Earth, Planetary and Space Sciences (SGEPSS); The Seismological Society of Japan; The Volcanological Society of Japan; The Geodetic Society of Japan; The Japanese Society for Planetary Sciences; TERRAPUB.

doi:10.5047/eps.2013.07.006 these separate inversions, joint inversions have been conducted using strong motions and static displacements by Horikawa et al. (1996), and using strong motions, teleseismic body waves, and static displacements by Wald (1996) and Yoshida et al. (1996). 1D stratified and half-space velocity structure models were also used in these studies.

The use of a 3D velocity structure model and the calculation of 3D Green's functions are very useful methods for separating the effects of the source and site when the time duration of strong motions is longer than the duration of the rupture process. In addition, the use of 3D strong-motion Green's functions can result in an improvement of the fitting between the observed and synthetic data, especially in later phases. The combined use of geodetic and strong-motion data can also provide a stabilizing constraint on the slip distribution (Wald and Graves, 2001). For these reasons, in this study, we refine a 3D velocity structure model and calculate 3D Green's functions for the strong-motion and geodetic data in the Osaka basin in order to incorporate the effects of a 3D velocity structure. As in previous studies, we also use 1D stratified velocity structure models for teleseismic and strong-motion data outside the Osaka basin. A half-space velocity structure model is used for geodetic data outside the Osaka basin. We then performed a joint inversion of strong motions, static displacements, and teleseismic body waves.

According to Graves and Wald (2001), the use of wellcalibrated 3D Green's functions provides very good resolution of the slip distribution of a source model, and adequately separates source and 3D propagation effects. In contrast, using a set of inexact 3D Green's functions allows only partial recovery of the slip distribution. This indi- 
Table 1. Parameters of each layer in the 3D velocity structure model. The sediment-bedrock interface $z$ varies station by station. $r_{1}$ and $r_{2}$ represent the common proportionality constants of Kagawa et al. (2004).

\begin{tabular}{ccccccc}
\hline Layer & $\begin{array}{c}V \mathrm{p} \\
(\mathrm{km} / \mathrm{s})\end{array}$ & $\begin{array}{c}V \mathrm{~s} \\
(\mathrm{~km} / \mathrm{s})\end{array}$ & $\begin{array}{c}\text { Density } \\
\left(\mathrm{g} / \mathrm{cm}^{3}\right)\end{array}$ & Qp & Qs & $\begin{array}{c}\text { Depth of top surface } \\
(\mathrm{km})\end{array}$ \\
\hline Sedimentary layer 1 & 1.60 & 0.35 & 1.7 & 120 & 60 & 0 \\
Sedimentary layer 2 & 1.80 & 0.55 & 1.8 & 200 & 100 & $\mathrm{r}_{1} \mathrm{z}$ \\
Sedimentary layer 3 & 2.50 & 1.00 & 2.1 & 250 & 125 & $\mathrm{r}_{2} \mathrm{z}$ \\
Bedrock 1 & 5.50 & 3.20 & 2.6 & 300 & 150 & $\mathrm{z}$ \\
Bedrock 2 & 6.00 & 3.46 & 2.7 & 500 & 250 & 2 \\
Bedrock 3 & 6.60 & 3.81 & 3.0 & 800 & 400 & 22 \\
Bedrock 4 & 7.80 & 4.50 & 3.2 & 1000 & 500 & 32 \\
\hline
\end{tabular}

Table 2. Source parameters of the three aftershocks used in the refinement of the velocity structure model. These parameters were determined by Katao et al. (1997).

\begin{tabular}{cccccccc}
\hline Event & $M_{\mathrm{JMA}}$ & $\begin{array}{c}\text { Longitude } \\
\left({ }^{\circ} \mathrm{E}\right)\end{array}$ & $\begin{array}{c}\text { Latitude } \\
\left({ }^{\circ} \mathrm{N}\right)\end{array}$ & $\begin{array}{c}\text { Depth } \\
(\mathrm{km})\end{array}$ & $\begin{array}{c}\text { Strike } \\
\left({ }^{\circ}\right)\end{array}$ & $\begin{array}{c}\text { Dip } \\
\left({ }^{\circ}\right)\end{array}$ & $\begin{array}{c}\text { Rake } \\
\left({ }^{\circ}\right)\end{array}$ \\
\hline $1995 / 1 / 2523: 15$ & 5.1 & 135.325 & 34.784 & 14.08 & 59 & 78 & 183 \\
$1995 / 2 / 216: 04$ & 4.0 & 135.052 & 34.585 & 13.15 & 325 & 33 & 173 \\
$1995 / 2 / 216: 19$ & 4.2 & 135.161 & 34.684 & 17.30 & 179 & 35 & 89 \\
\hline
\end{tabular}

cates that a $3 \mathrm{D}$ velocity structure model should be carefully validated before performing a source inversion. Therefore, we also perform this validity test and refine the $3 \mathrm{D}$ velocity structure through waveform modeling of ground motion data from aftershocks.

\section{Refinement of the 3D Velocity Structure Model}

The velocity structure of the Osaka basin has been extensively investigated in recent years. Our initial model for the refinement was as follows. We adopted the $3 \mathrm{D}$ sedimentbedrock interface estimated by Afnimar et al. (2002), who carried out a joint inversion of refraction and gravity data. For the velocity structure of the bedrock, we used the same 1D stratified velocity structure model as in Yoshida et al. (1996). Table 1 lists this bedrock part and three sedimentary layers of the basin part of our initial model. The top surface of each sedimentary layer is set to be proportional to the depth of the sediment-bedrock interface. The common proportionality constants were estimated from microtremor array measurements and seismic reflection survey data by Kagawa et al. (2004).

The sediment-bedrock interface $z$ in Table 1 varies from station to station, and the depths of the top surfaces for sedimentary layers 2 and 3 are $r_{1} z$ and $r_{2} z$, respectively, where $r_{1}$ and $r_{2}$ are common proportionality constants. In our refinement procedure, $r_{1}, r_{2}$, and $z_{j}(j=1,2, \ldots)$, where $j$ represents the number of stations, are treated as unknowns. We calibrated these unknowns using ground motion data from aftershocks.

We chose the three aftershocks listed in Table 2 as target events. Data from the Kobe area were used in the refinement because the velocity structure model in this area strongly affects 3D Green's functions. They were recorded by the Committee of Earthquake Observation and Research in the Kansai Area (CEORKA), Iwata et al. (1996), and the Earthquake Research Institute, University of Tokyo (see Nagano et al., 1999).

In modeling ground motions, we calculated synthetic velocity waveforms using the finite element method (FEM) with voxel meshes (Koketsu et al., 2004; Ikegami et al., 2008) with intervals of $40 \mathrm{~m}$. The source time function was a smoothed ramp function with a rise time of $0.5 \mathrm{~s}$. Next, we checked whether the synthetic waveforms agreed with the observed ground motions in the frequency range $0.3-1.0 \mathrm{~Hz}$. If not, we calibrated the depth $z$ beneath a station and the common proportionality constants $r_{1}$ and $r_{2}$ by trial and error, then three-dimensionally combined them with the depths surrounding the station using the interpolating method of Smith and Wessel (1990). Thereafter, we again performed waveform modeling. We repeated this successive procedure until the synthetic waveforms fit the observed waveforms well with regard to their specific phases and travel times and the sum of squares of the residual of their waveforms shows the smallest value. In our refined model, the common proportionality constants $r_{1}$ and $r_{2}$, which were 0.19 and 0.47 (Kagawa et al., 2004) in the initial model, were revised to 0.08 and 0.39 , respectively.

Figure 1 shows the resultant $S$-wave velocity structures beneath the stations and waveform comparisons for the aftershock at 16:19 on February 2, 1995. The observed waveforms were compared with the synthetic waveforms computed with the initial and refined models.

\section{Source Inversion}

We performed a joint inversion of strong motions, static displacements and teleseismic body waves. For this inversion, we used the method of Yoshida et al. (1996) which is based on the formulation of multiple time windows. The inversion was stabilized by imposing a smoothness constraint with a discrete Laplacian in space and time, whose weight is determined by minimizing Akaike's Bayesian Information Criterion (Akaike, 1980). We assumed two fault planes 

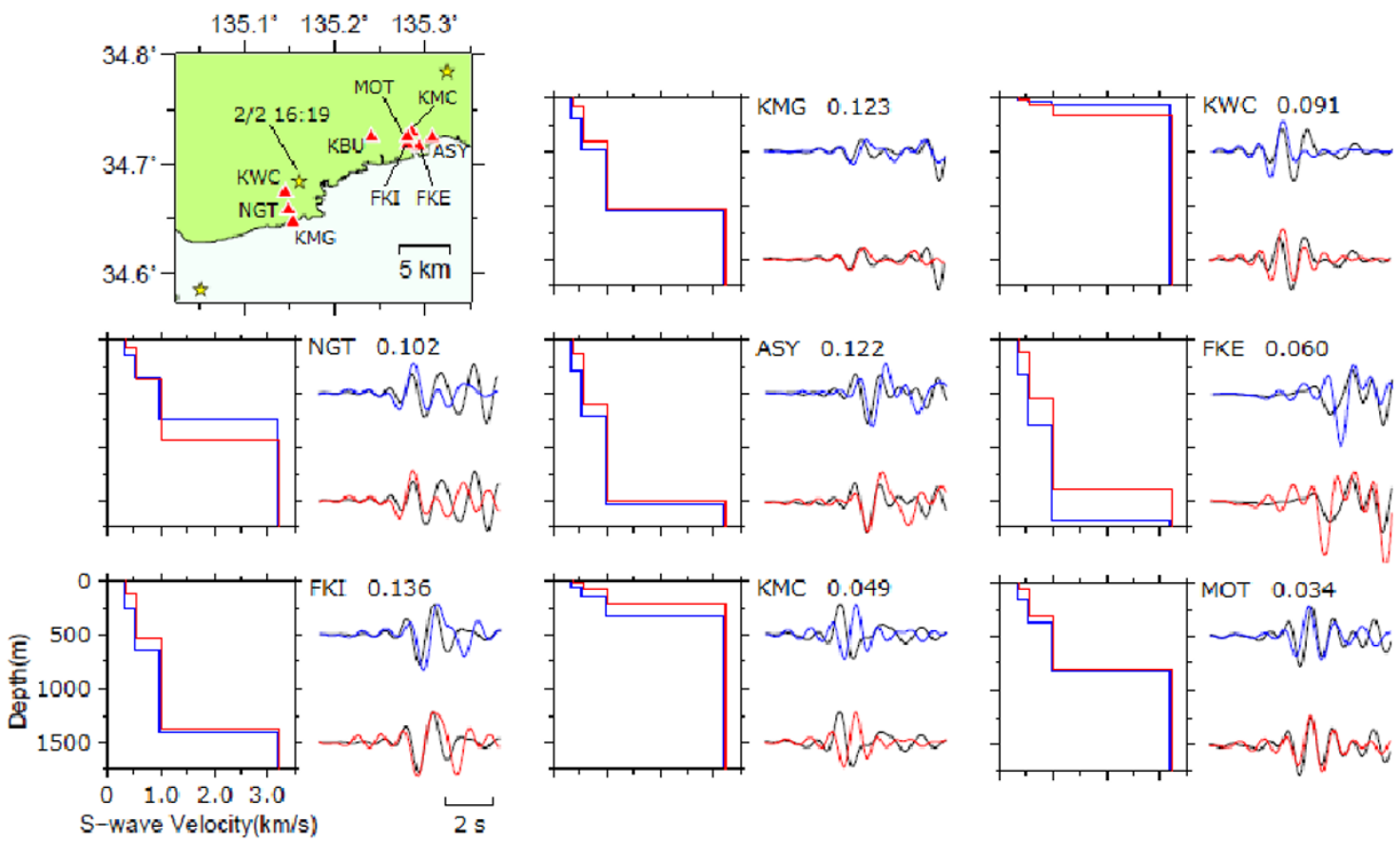

Fig. 1. The $S$-wave velocity structure beneath each station in the initial model (blue lines) and refined model (red lines), and comparison of transverse components for the aftershock at 16:19 on February 2, 1995, with the observed velocity waveforms (black traces), the synthetic waveforms calculated from the initial model (blue traces), and the refined model (red traces). The stations (red triangles) and three aftershocks (yellow stars) used in the refinement are plotted in the uppermost and leftmost map. The number above the traces is the maximum amplitude of the observed velocity waveform in $\mathrm{cm} \mathrm{s}^{-1}$. The $S$-wave velocity structure and waveforms at station KBU are not shown because the initial model of KBU is good enough and therefore was not refined.
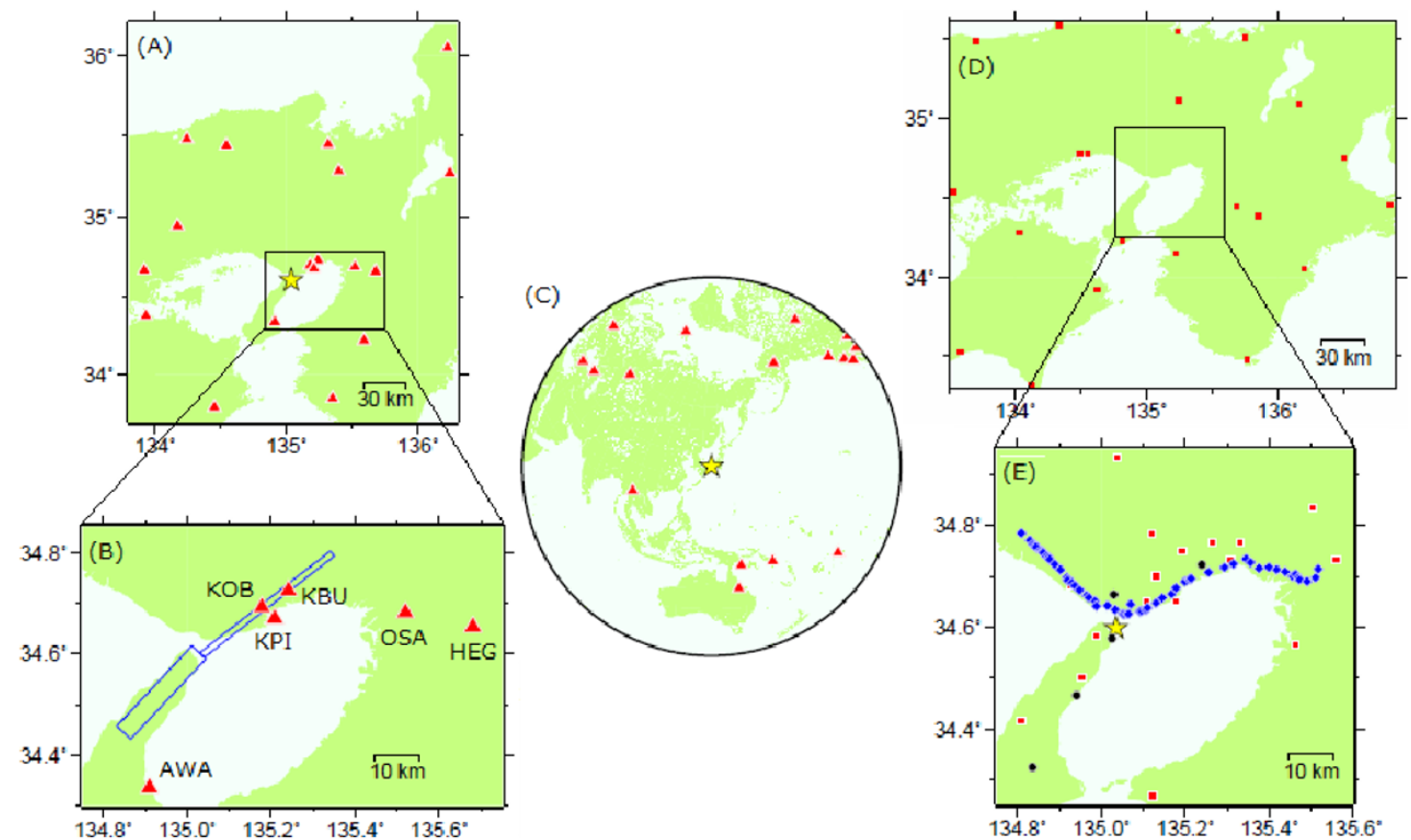

Fig. 2. Stations with (A) strong motions, (B) strong motions where 3D Green's functions were calculated, (C) teleseismic body waves, and static displacements where (D) half-space and (E) 3D Green's functions were calculated. The epicenter is marked by a yellow star. Red triangles in (A), (B) and (C) represent the stations. In (D) and (E), the stations that measure horizontal displacements (red), vertical displacements along a leveling route (blue) and three component displacements (black) are plotted. (B) also shows the two fault planes (blue rectangles).

as shown in Fig. 2. One fault plane is in Awaji Island and the other is in the Kobe area. The strike and dip of the former were set as $43^{\circ}$ and $75^{\circ}$, and those of the latter as $52^{\circ}$ and $95^{\circ}$. The two fault planes were divided into $4 \times 4 \mathrm{~km}^{2}$ subfaults. The slip vector on each subfault was represented by a linear combination of two components in the direction of $180^{\circ} \pm 45^{\circ}$, and the time history of each component was represented by three ramp functions with a rise time of $1 \mathrm{~s}$. 
(A)

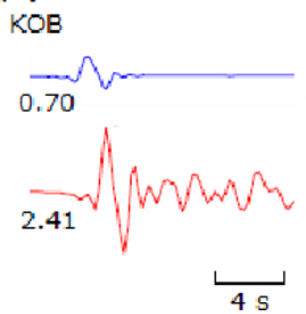

OSA
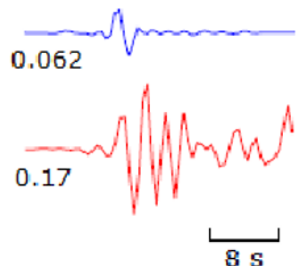

(B)

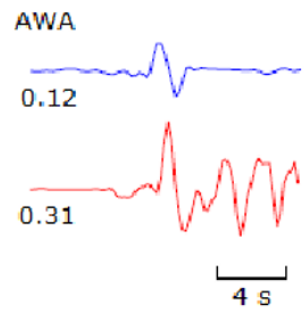

Fig. 3. Comparisons of the $1 \mathrm{D}$ (blue lines) and 3D (red lines) strong-motion Green's functions with rake angles of $225^{\circ}$ for (A) the NS components from a subfault in the deeper part of the Kobe fault, and (B) the EW components from a subfault in the shallow part along the Nojima fault. The filtering and sampling for these Green's functions are the same as those in Yoshida et al. (1996). The maximum amplitude is given in $\mathrm{cm}^{-1}$ below $^{-1}$ each trace. We can see in (A) that the 3D Green's function at station KOB has a notably larger amplitude than the 1D Green's function.
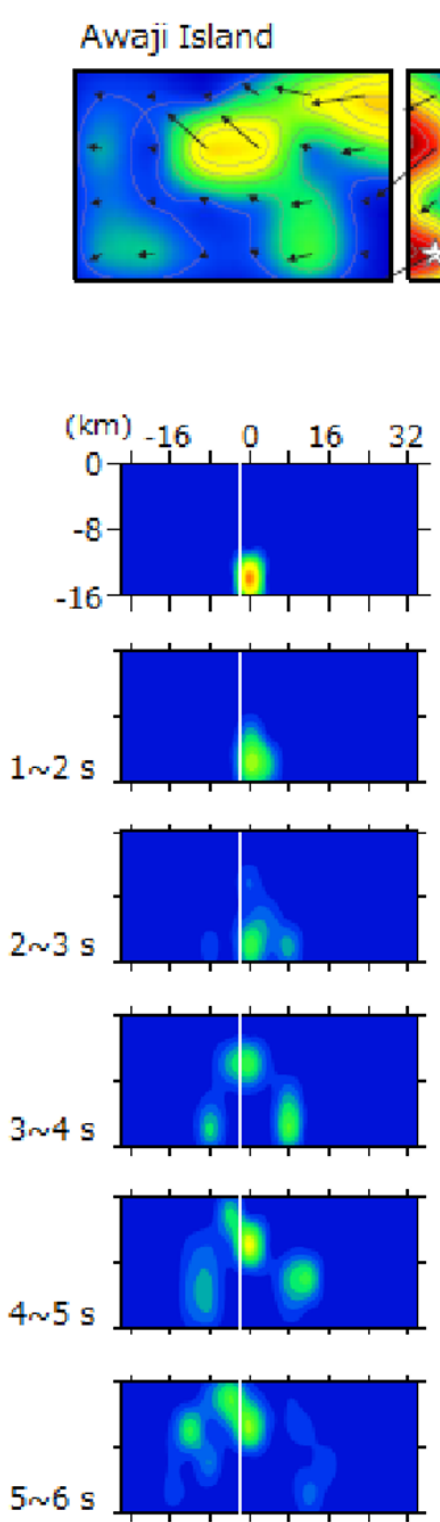

(A)

Kobe

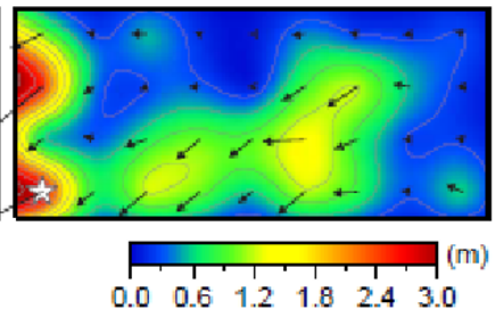

(B)
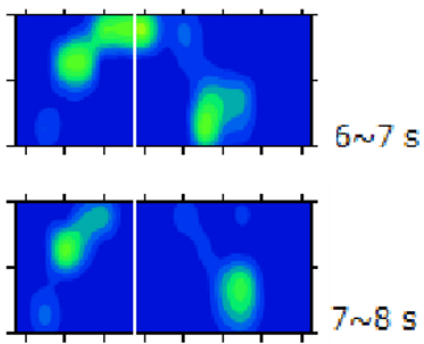

m)
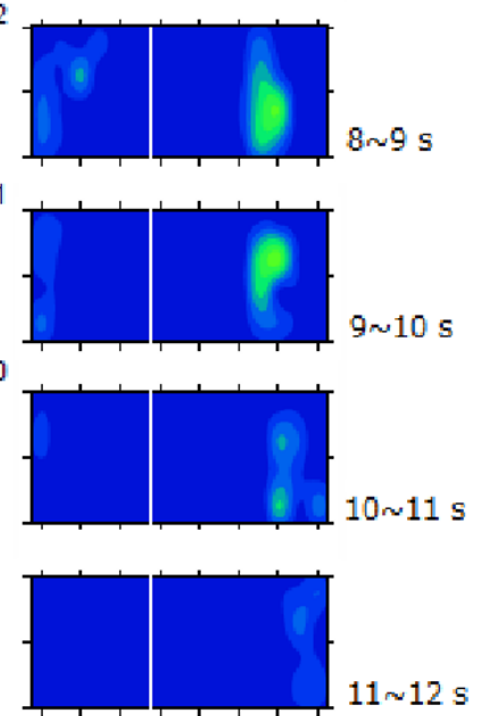

Fig. 4. (A) Final slip distribution obtained by the inversion, and (B) the growth of rupture depicted by the snapshots of slip distribution at every $1 \mathrm{~s}$. Arrows and a white star in (A) denote subfault slips on the hanging walls and the hypocenter, respectively.

We introduced a positivity constraint to confine the slip angles within $180^{\circ} \pm 45^{\circ}$.

The fault model described above is the same as that of Yoshida et al. (1996). However, they used only 1D strat- ified layer velocity structure models to calculate Green's functions for strong motions and teleseismic body waves, and only a half-space velocity structure model for static displacements. In our source inversion, we used a 3D velocity 


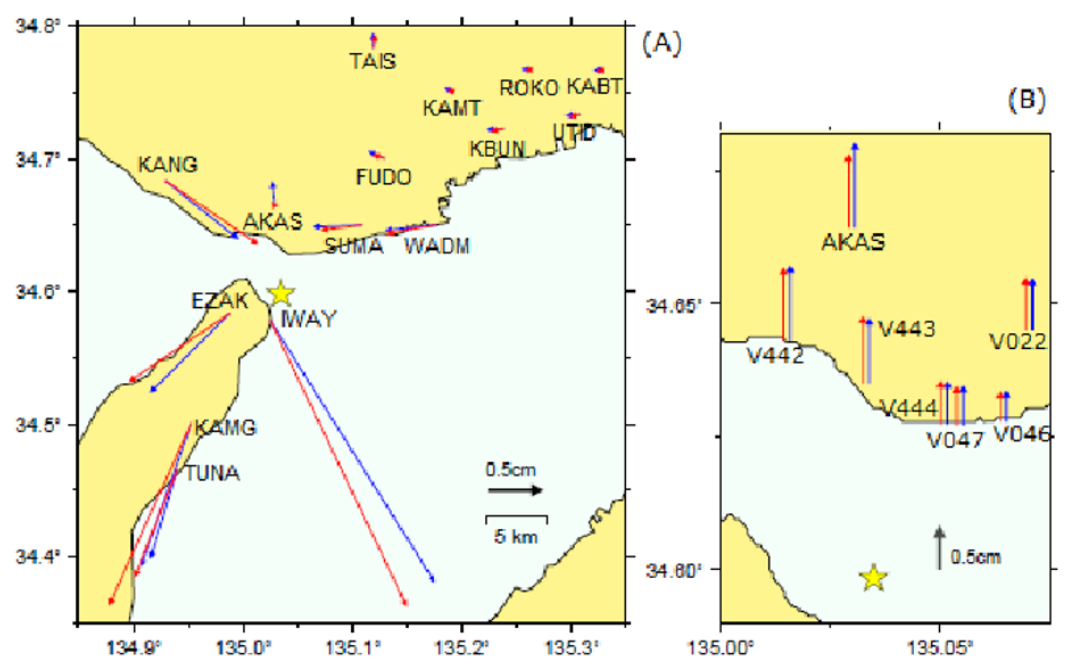

Fig. 5. Comparisons of the 3D (red arrows) and half-space (blue arrows) geodetic Green's functions. (A) The horizontal displacements of the rake angle of $135^{\circ}$ for a subfault in the shallow part along the Nojima fault, and (B) the vertical displacements of the rake angle of $225^{\circ}$ for a subfault beneath the Akashi Strait, are shown. The yellow star represents the epicenter.

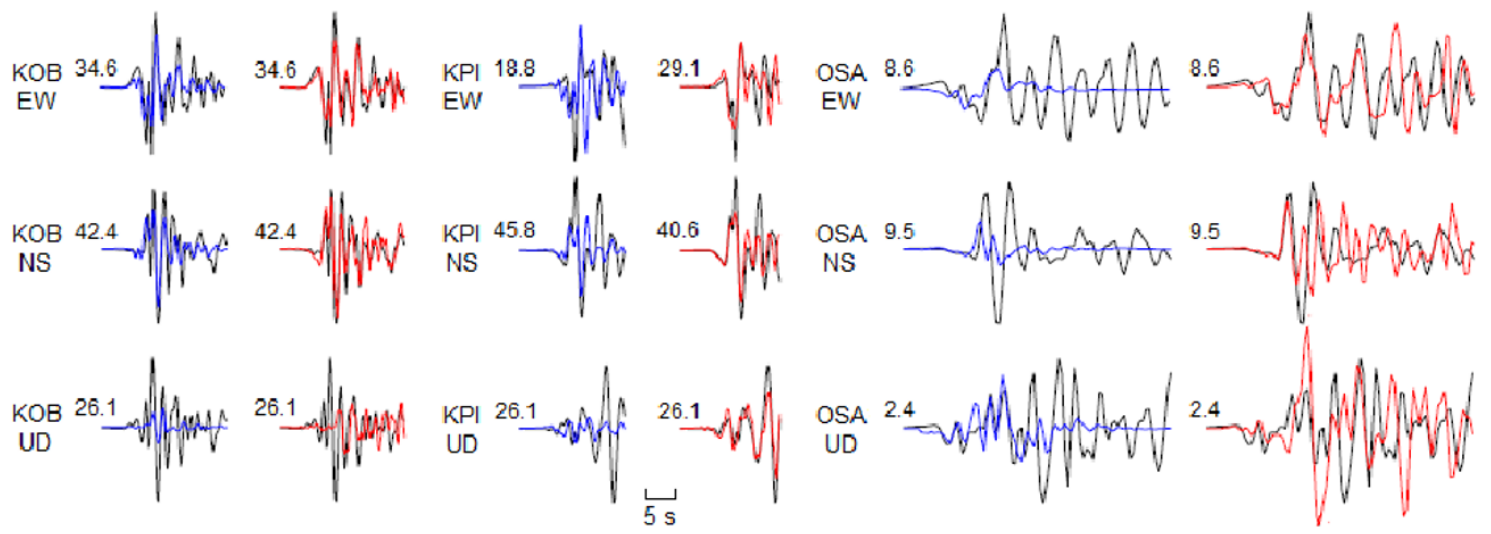

Fig. 6. Comparisons of the observed (black) and synthetic waveforms from inversion using 1D (blue) or 3D (red) Green's functions at stations KOB, KPI and OSA. The maximum amplitude is given in $\mathrm{cm} \mathrm{s}^{-1}$ above each trace. Because the sensor orientation of the borehole seismometer at station KPI has been corrected, the maximum amplitudes for the EW and NS components are different between the blue and red traces.

structure model refined as mentioned in the previous section for the strong-motion and geodetic data for the Osaka basin. We used the same Green's functions as Yoshida et al. (1996) for the data outside the Osaka basin. The datasets shown in Fig. 2 and their time duration, weights, filtering and sampling were also the same as those in Yoshida et al. (1996). We note that the sensor orientation of the borehole seismometer installed at the strong-motion station KPI has been corrected.

For calculating 3D Green's functions, we again used the FEM with voxel meshes. We then derived geodetic Green's functions by averaging calculated ground motions from about $50 \mathrm{~s}$ to $70 \mathrm{~s}$.

\section{Conclusions and Discussion}

In this section, we summarize and discuss our results mainly by comparing them with those of Yoshida et al. (1996).

In our source model, the rupture velocity for the first time window was set as $3.1 \mathrm{~km} / \mathrm{s}$, which is roughly equivalent to $90 \%$ of the $S$-wave velocity at the depth of the hypocenter and provides the best fit to the observed data. This rupture velocity is higher than that of Yoshida et al. (1996), which was $2.5 \mathrm{~km} / \mathrm{s}$. Unlike in the case of their model, the sedimentary layers are included in our 3D velocity structure model. Since these additional sedimentary layers delay the travel times of 3D strong-motion Green's functions at stations inside the 3D basin structure, such as KOB and OSA (see Fig. 3(A)), the rupture velocity was set to be higher than that of Yoshida et al. (1996) to compensate for these delays in the travel times. The rupture velocity in our model is also comparable with that of Horikawa et al. (1996), or Sekiguchi et al. (2000), both of whose velocity structure models include sedimentary layers.

Figure 4 illustrates the slip distribution and the snapshots of rupture during each of the 1-s time windows. The total seismic moment was estimated to be about $2.1 \times 10^{19} \mathrm{~N}$ $\mathrm{m}\left(M_{\mathrm{w}}=6.8\right)$, which is slightly smaller than those of the joint inversions performed by Wald (1996) and Yoshida et al. (1996). In the slip distribution, a very large slip, with a maximum value of $2.9 \mathrm{~m}$ near the hypocenter, is found beneath the Akashi Strait. We can also see two other zones of 
large slip: one along the Nojima fault in the northern, shallow part of Awaji Island, and the other in the deeper part of the Kobe fault. Although this slip pattern consisting of these large-slip zones is similar to that mentioned by Yoshida $e t$ al. (1996), the amount of slip in each zone is different. For example, the maximum slip along the Nojima fault in our model is less than that reported by Yoshida et al. (1996) by about $0.3 \mathrm{~m}$. This may be attributed to the sedimentary layers we introduced. These layers caused a larger amplification of the main phases in the 3D strong-motion Green's functions, as shown in Fig. 3(B), and resulted in smaller slips than those in Yoshida et al. (1996) being recovered to match the observed data at station AWA. On the other hand, the slip zone beneath the Akashi Strait looks more compact but has greater slips than that in Yoshida et al. (1996). These slips, whose vertical components of geodetic Green's functions indicate uplift (see Fig. 5(B)), occurred to explain the considerable uplifts observed at the stations near the Akashi Strait. In addition, the larger-slip zone under the city center of Kobe spreads through a wider area than Wald (1996) and Yoshida et al. (1996) indicated, and this zone probably contributed to the violent ground motions and extreme disaster in the city.

Figure 4(B) shows two rupture propagations in our source model. One propagated toward the shallow part along the Nojima fault, and the other propagated from the deeper part beneath the Akashi Strait to the zone beneath the city center of Kobe. This figure also shows a large slip around the hypocenter in the early stage, and this consequently contributes to the large final slip in this area.

The use of 3D strong-motion Green's functions in our inversion resulted in a better fit to the observed strong motions. For the strong motions, the variance reduction, which measures the degree of agreement between the observed and synthetic data, was nearly $10 \%$ higher than that in Yoshida et al. (1996). Figure 6 shows that the synthetic waveforms are generally consistent with the observations at the stations KOB, KPI and OSA in the Osaka basin. For the static displacements, we have confirmed that the degree of fit to the observed data was almost equivalent to that of Yoshida et al. (1996). This indicates that static displacements are less sensitive to a 3D velocity structure than strong motions. Figure 5 shows the comparison of 3D and half-space geodetic Green's functions, where only small differences can be seen.

Acknowledgments. We thank CEORKA, GSI, JMA, JUNCO, the Kobe city government, Prof. Iwata (Kyoto Univ.), and Prof. Nagano (Tokyo Science Univ.) for providing data. We used GMT for drawing the figures. We also thank two reviewers Atsushi Nozu and Haruko Sekiguchi, and the Editor Tatsuhiko Hara for helpful comments.

\section{References}

Afnimar, K. Koketsu, and K. Nakagawa, Joint inversion of refraction and gravity data for the three-dimensional topography of a sediment- basement interface, Geophys. J. Int., 151, 243-254, 2002.

Akaike, H., Likelihood and the Bayes Procedure, 143-166, Univ. Press, Valencia, Spain, 1980.

Furumura, T. and K. Koketsu, Specific distribution of ground motion during the 1995 Kobe earthquake and its generation mechanism, Geophys. Res. Lett., 25, 785-788, 1998.

Graves, R. W. and D. J. Wald, Resolution analysis of finite fault source inversion using one- and three-dimensional Green's functions, 1. Strong motions, J. Geophys. Res., 106, 8745-8766, 2001.

Hashimoto, M., T. Sagiya, H. Tsuji, Y. Hatanaka, and T. Tada, Co-seismic displacement of the 1995 Hyogo-ken Nanbu Earthquake, J. Phys. Earth, 44, 255-279, 1996.

Horikawa, H., K. Hirahara, Y. Umeda, M. Hashimoto, and F. Kusano, Simultaneous inversion of geodetic and strong-motion data for the source process of the Hyogo-ken Nanbu, Japan, Earthquake, J. Phys. Earth, 44, 455-471, 1996.

Ide, S., M. Takeo, and Y. Yoshida, Source model of the 1995 Hyogo-ken Nanbu Earthquake determined by near-field strong-motion records, $J$. Phys. Earth, 44, 649-653, 1996.

Ikegami, Y., K. Koketsu, T. Kimura, and H. Miyake, Finite-element simulations of long-period ground motions: Japanese subduction-zone earthquakes and the 1906 San Francisco Earthquake, J. Seismol., 12, 161$172,2008$.

Iwata, T., K. Hatayama, H. Kawase, and K. Irikura, Site amplification of ground motions during aftershocks of the 1995 Hyogo-ken Nanbu Earthquake in severely damaged zone-array observation of ground motions at Higashinada ward, Kobe city, Japan, J. Phys. Earth, 44, 553561, 1996.

Kagawa, T., B. Zhao, K. Miyakoshi, and K. Irikura, Modeling of 3D basin structures for seismic wave simulations based on available information on the target area: Case study of the Osaka Basin, Japan, Bull. Seismol. Soc. Am., 94, 1353-1368, 2004.

Katao, H., N. Maeda, Y. Hiramatsu, Y. Iio, and S. Nakao, Detailed mapping of focal mechanisms in/around the 1995 Hyogo-ken Nanbu Earthquake rupture zone, J. Phys. Earth, 45, 105-119, 1997.

Kawase, H., The cause of the damage belt in Kobe: "The basin-edge effect," Constructive interference of the direct S-wave with the basininduced diffracted/Rayleigh waves, Seismol. Res. Lett., 67, 25-34, 1996.

Kikuchi, M. and H. Kanamori, Rupture process of the Kobe, Japan, Earthquake of Jan. 17, 1995, determined from teleseismic body waves, $J$. Phys. Earth, 44, 429-436, 1996.

Koketsu, K., H. Fujiwara, and Y. Ikegami, Finite-element simulation of seismic ground motion with a voxel mesh, Pure Appl. Geophys., 161, 2183-2198, 2004

Nagano, M., K. Kudo, and M. Takemura, Simulation analyses of the array strong motion records from the aftershocks of the 1995 Hyogo-ken Nanbu Earthquake $\left(M_{j}=7.2\right)$ regarding the irregularity of the underground structure in Nagata ward, Kobe, J. Seismol. Soc. Jpn., 52, 25-41, 1999

Sekiguchi, H., K. Irikura, and T. Iwata, Fault geometry at the rupture termination of the 1995 Hyogo-ken Nanbu Earthquake, Bull. Seismol. Soc. Am., 90, 117-133, 2000.

Smith, W. H. F. and P. Wessel, Gridding with continuous curvature splines in tension, Geophysics, 55, 293-305, 1990.

Wald, D. J., Slip history of the 1995 Kobe, Japan, Earthquake determined from strong motion, teleseismic, and geodetic data, J. Phys. Earth, 44, 489-503, 1996.

Wald, D. J. and R. W. Graves, Resolution analysis of finite fault source inversion using one-and three-dimensional Green's functions, 2. Combining seismic and geodetic data, J. Geophys. Res., 106, 8767-8788, 2001.

Yoshida, S., K. Koketsu, B. Shibazaki, T. Sagiya, T. Kato, and Y. Yoshida, Joint inversion of near- and far-field waveforms and geodetic data for the rupture process of the 1995 Kobe Earthquake, J. Phys. Earth, 44, 437-454, 1996.

Y. Guo (e-mail: guo@eri.u-tokyo.ac.jp), K. Koketsu, and T. Ohno 